Article

\title{
Rumen and Serum Metabolomes in Response to Endophyte-Infected Tall Fescue Seed and Isoflavone Supplementation in Beef Steers
}

\author{
Taylor B. Ault-Seay ${ }^{1}$, Emily A. Melchior-Tiffany ${ }^{1,+}{ }^{\circledR}$, Brooke A. Clemmons ${ }^{1, \ddagger}$, Juan F. Cordero ${ }^{1}$, \\ Gary E. Bates ${ }^{2}$, Michael D. Flythe ${ }^{3}{ }^{\mathbb{D}}$, James L. Klotz ${ }^{3}$, Huihua Ji ${ }^{4}$, Jack P. Goodman ${ }^{5}{ }^{(}$, \\ Kyle J. McLean ${ }^{1}$ and Phillip R. Myer ${ }^{1, * \mathbb{D}}$ \\ 1 Department of Animal Science, University of Tennessee, Knoxville, TN 37996, USA; \\ tault1@vols.utk.edu (T.B.A.-S.); eam@nmsu.edu (E.A.M.-T.); Brooke.Clemmons@tamuc.edu (B.A.C.); \\ Juan.Cordero@utk.edu (J.F.C.); kmclea10@utk.edu (K.J.M.) \\ 2 Department of Plant Sciences, University of Tennessee, Knoxville, TN 37996, USA; gbates@utk.edu \\ 3 USDA-ARS, Forage-Animal Production Research Unit, Lexington, KY 40546, USA; \\ michael.flythe@ars.usda.gov (M.D.F.); James.Klotz@ars.usda.gov (J.L.K.) \\ 4 Kentucky Tobacco Research and Development Center, University of Kentucky, Lexington, KY 40546, USA; \\ hji4@email.uky.edu \\ 5 Department of Plant and Soil Sciences, University of Kentucky, Lexington, KY 40546, USA; \\ jpgood2@email.uky.edu \\ * Correspondence: pmyer@utk.edu; Tel.: +1-865-974-3184 \\ + Current Address: Department of Animal and Range Sciences, New Mexico State University, \\ Las Cruces, NM 88003, USA. \\ $\ddagger$ Current Address: Department of Agriculture, Texas A\&M University-Commerce, \\ Commerce, TX 75428, USA.
}

Received: 4 November 2020; Accepted: 24 November 2020; Published: 26 November 2020

\begin{abstract}
Fescue toxicosis impacts beef cattle production via reductions in weight gain and muscle development. Isoflavone supplementation has displayed potential for mitigating these effects. The objective of the current study was to evaluate isoflavone supplementation with fescue seed consumption on rumen and serum metabolomes. Angus steers $(n=36)$ were allocated randomly in a $2 \times 2$ factorial arrangement of treatments including endophyte-infected $(\mathrm{E}+)$ or endophyte-free $(\mathrm{E}-)$ tall fescue seed, with $(\mathrm{P}+)$ or without $(\mathrm{P}-)$ isoflavones. Steers were provided a basal diet with fescue seed for 21 days, while isoflavones were orally administered daily. Following the trial, blood and rumen fluid were collected for metabolite analysis. Metabolites were extracted and then analyzed by UPLC-MS. The MAVEN program was implemented to identify metabolites for MetaboAnalyst 4.0 and SAS 9.4 statistical analysis. Seven differentially abundant metabolites were identified in serum by isoflavone treatment, and eleven metabolites in the rumen due to seed type $(p<0.05)$. Pathways affected by treatments were related to amino acid and nucleic acid metabolism in both rumen fluid and serum $(p<0.05)$. Therefore, metabolism was altered by fescue seed in the rumen; however, isoflavones altered metabolism systemically to potentially mitigate detrimental effects of seed and improve animal performance.
\end{abstract}

Keywords: beef cattle; endophyte; ergot alkaloid; fescue toxicosis; isoflavone; metabolites

Key Contribution: As fescue toxicosis causes multiple symptoms that negatively impact beef cattle performance, isoflavone consumption may reduce these effects. The current study found tall fescue seed type to mainly impact the rumen metabolome, while isoflavone supplementation affected the host metabolome in the serum, potentially improving animal growth and development during fescue toxicosis. 


\section{Introduction}

Tall fescue is the major forage used to feed cattle in pasture-based systems of the southeast and covers approximately 14 million hectares across the United States [1]. The advantage of tall fescue is hardiness of the plants attributed to the presence of a fungal endophyte (Epichloë coenophialum, formerly known as Neotyphodium coenophialum and Acremonium coenophialum) living in a mutualistic relationship with the plant [2]. However, the endophyte produces ergot alkaloids that are toxic to animals that consume them for an extended period of time [3]. Ergot alkaloids are able to bind biogenic amine receptors on blood vessels, resulting in vasoconstriction throughout the body [4-6]. This results in a condition known as fescue toxicosis, which is commonly observed by the animal's inability to thermoregulate [7], poor reproductive performance [1], and reduced average daily gain [8], significantly reducing overall animal performance. Therefore, researchers are tasked with identifying management methods and therapeutics to alleviate these consequences to cattle producers.

Pasture management methods have been evaluated for reducing the impact of fescue toxicosis in cattle. Inter-seeding of legumes, such as red clover, to mitigate the effects of fescue toxicosis has proved beneficial in cattle grazing endophyte-infected tall fescue [9]. Recent research has found phytoestrogenic compounds, known as isoflavones, present in red clover may be responsible for reducing the effects of fescue toxicosis. Isoflavones act as an agonist on the $\beta$-adrenergic receptors present on blood vessels to promote vasodilation [10], reversing the effects of ergot alkaloid induced vasoconstriction. Additionally, isoflavones act as a natural antibiotic selective against hyper-ammonia-producing bacteria (HAB) and some cellulolytic and amylolytic bacteria [11,12]. The reduction of ammonia levels as a result of less HAB in the rumen allows more amino acids to be absorbed and used by the ruminant, while altered celluloytic and amylolytic bacteria can influence the production of volatile fatty acids for energy. Therefore, the increase in blood flow and altered rumen fermentation may improve nutrient delivery and utilization for host metabolic processes contributing to animal growth.

The objective of the present study is to evaluate the effect of isoflavone supplementation with tall fescue seed consumption on beef steer's rumen and serum metabolomes. Ruminal and circulating metabolites may provide insights into altered bacterial and host metabolic functions that improve steer performance on endophyte infected tall fescue with the administration of isoflavones.

\section{Results}

\subsection{Global Rumen Fluid and Serum Metabolome Comparison}

An orthogonal partial least squares discriminant analysis (O-PLS-DA) was used to depict the relationship between the global rumen and serum metabolomes, which illustrated distinct separation between the two metabolomes (Figure 1). A heatmap was also used to visualize the top 25 rumen fluid and serum metabolites by individual steer (Figure 2). The heatmap supports that there is very little similarity between the overall ruminal and circulating metabolites.

\subsection{Rumen Fluid Metabolome}

All identified rumen fluid metabolites are presented in Supplementary File 1 with means and standard errors of the mean by treatment combination group. To visualize the effect between steers of the $\mathrm{E}+\mathrm{P}+$ and $\mathrm{E}-\mathrm{P}-$ groups on the rumen fluid metabolome, a partial least squares discriminant analysis (PLS-DA) was created and a significant distinct overlap among seed type was noted (Figure 3). Correlation analyses were performed to analyze the correlation of individual rumen metabolites with the treatment combination groups, and variable importance in the projection (VIP) scores were generated to determine the metabolites that contributed to variation in rumen fluid metabolomes among treatment combination groups. Xylose was negatively correlated with the treatments $(\mathrm{r}=-0.57)$ and had one of the greatest impacts on metabolome differences among all treatments $(p=0.01)$ (Figure 4 , Table 1). Individual metabolite and metabolic pathway analyses were not significantly impacted by the interaction of seed type and isoflavone treatments $(p>0.05)$. 
The rumen metabolome was analyzed by the main effects of seed type and isoflavone treatment. In order to visualize the difference in rumen fluid metabolomes, an O-PLS-DA was generated for the main effects of seed type (Figure 5A) and isoflavone treatment (Figure 5B). For seed type and isoflavone treatment, partial separation was observed between endophyte-infected and endophyte-free seed (Figure 5A). Additionally, partial separation was observed between steers receiving isoflavones and those that did not receive isoflavones (Figure 5B). Correlation analysis indicated hypoxanthine was negatively correlated $(\mathrm{r}=-0.56)$ and determined by VIP analysis to have a significant impact on the rumen fluid metabolome differences between endophyte-infected and endophyte-free seed treatments $(p=0.01$; Figure 6A; Table 1). For isoflavone treatments, trehalose/sucrose was positively correlated $(\mathrm{r}=0.06)$, but had no impact on the rumen fluid metabolome differences (Figure 6B). Metabolites that differed by seed type are presented in Table 1. Eleven metabolites differed significantly as a result of endophyte-infected versus endophyte-free treatments $(p<0.05$, Table 1$)$. No individual metabolite differences were observed in the rumen fluid as a result of isoflavone treatment. Metabolic pathways that differed significantly by seed type or isoflavone treatment are presented in Table 2 . Twenty metabolic pathways were affected by seed type, but only two pathways were affected by isoflavones $(p<0.05)$.

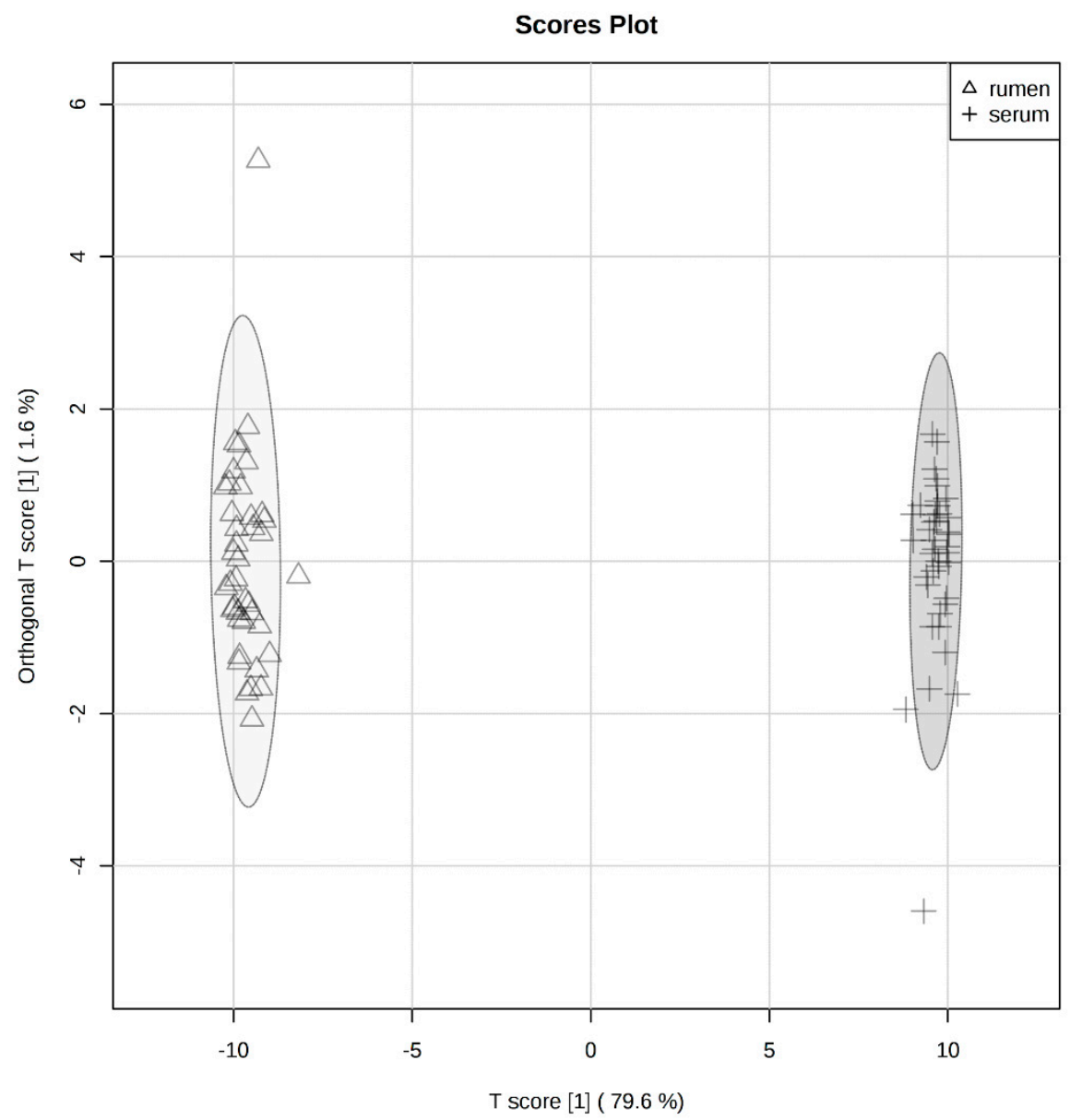

Figure 1. Orthogonal partial least squares discriminant analysis (O-PLS-DA) visualizing separation of rumen fluid (triangle) and serum (plus-sign) metabolomes. Ellipse represents a 95\% confidence interval. 


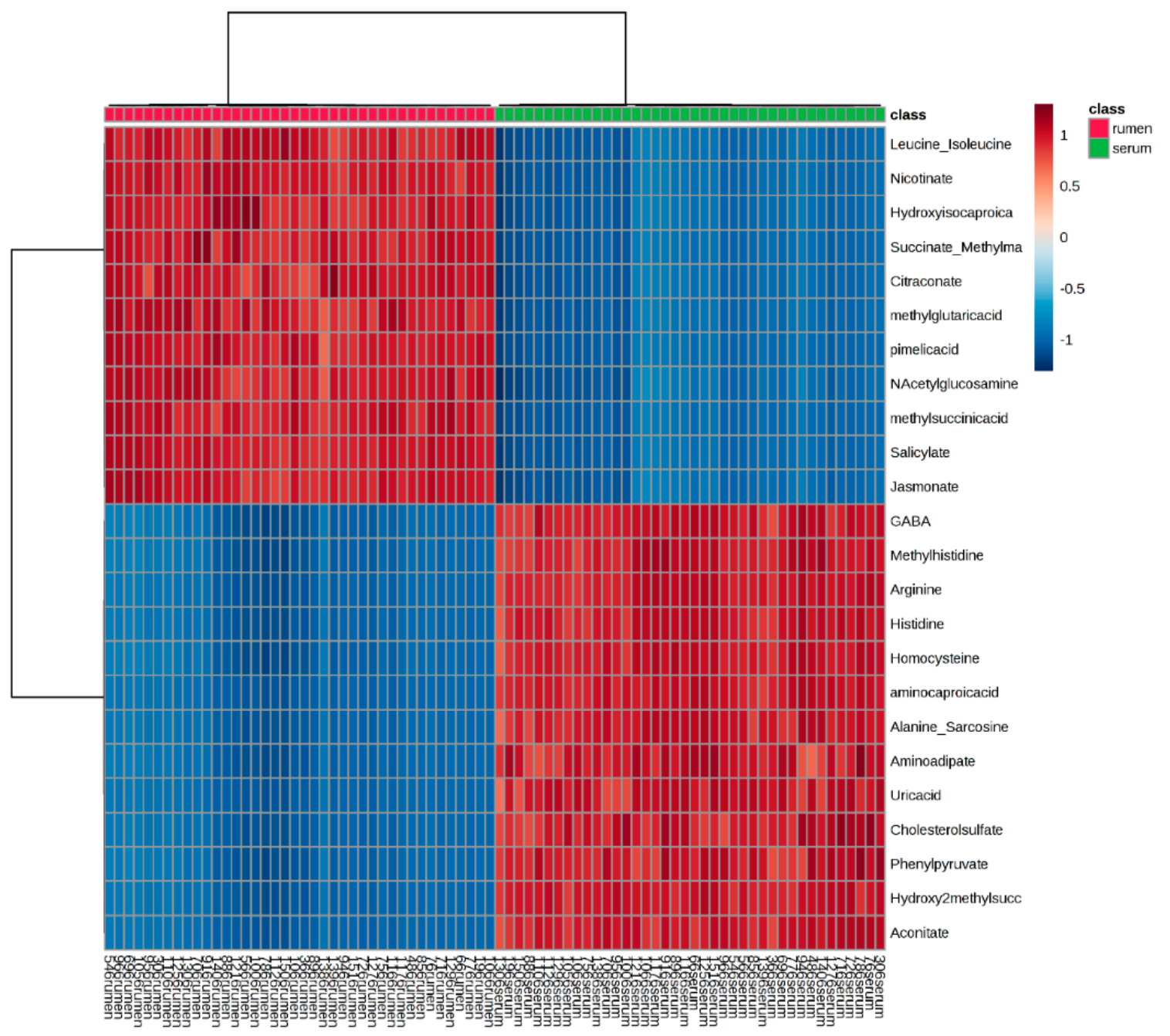

Figure 2. Heatmap of top 25 metabolites of rumen fluid and serum metabolomes by individual steers. Rumen fluid is represented by the red square at the top of the heatmap and serum metabolites are represented by the green squares.

Table 1. Rumen fluid metabolites that significantly differed by seed type.

\begin{tabular}{|c|c|c|c|}
\hline \multirow{2}{*}{ Metabolite } & \multicolumn{2}{|c|}{ Seed Type ${ }^{\dagger}$} & \multirow{2}{*}{$p$ Value $^{\epsilon}$} \\
\hline & $\mathrm{E}+$ & E- & \\
\hline Dihydroxybenzoate & $5.90 \times 10^{7} \pm 5.35 \times 10^{6 \mathrm{~B}}$ & $8.43 \times 10^{7} \pm 6.26 \times 10^{6 \mathrm{~A}}$ & 0.05 \\
\hline Adenine * & $2.30 \times 10^{7} \pm 1.13 \times 10^{7 \mathrm{~B}}$ & $6.84 \times 10^{7} \pm 1.32 \times 10^{7 \mathrm{~A}}$ & 0.02 \\
\hline $\mathrm{CMP} *$ & $9.17 \times 10^{5} \pm 7.64 \times 10^{5 B}$ & $3.17 \times 10^{6} \pm 8.95 \times 10^{5 \mathrm{~A}}$ & 0.04 \\
\hline Deoxyuridine * & $8.04 \times 10^{5} \pm 2.71 \times 10^{5 B}$ & $1.74 \times 10^{6} \pm 3.18 \times 10^{5 \mathrm{~A}}$ & 0.02 \\
\hline Glutamate* & $7.18 \times 10^{7} \pm 2.17 \times 10^{7 \mathrm{~B}}$ & $1.57 \times 10^{8} \pm 2.54 \times 10^{7 \mathrm{~A}}$ & 0.05 \\
\hline Guanosine * & $3.00 \times 10^{5} \pm 1.44 \times 10^{5 \mathrm{~B}}$ & $8.63 \times 10^{5} \pm 1.69 \times 10^{5 \mathrm{~A}}$ & 0.05 \\
\hline Homoserine/threonine & $1.02 \times 10^{7} \pm 8.90 \times 10^{5 \mathrm{~B}}$ & $6.65 \times 10^{6} \pm 7.60 \times 10^{5 \mathrm{~A}}$ & 0.05 \\
\hline Hypoxanthine * & $4.40 \times 10^{7} \pm 1.66 \times 10^{7 \mathrm{~B}}$ & $1.17 \times 10^{8} \pm 1.94 \times 10^{7 \mathrm{~A}}$ & 0.01 \\
\hline Uracil * & $5.76 \times 10^{7} \pm 1.19 \times 10^{7 \mathrm{~B}}$ & $1.08 \times 10^{8} \pm 1.39 \times 10^{7 \mathrm{~A}}$ & 0.02 \\
\hline Xanthine * & $1.79 \times 10^{8} \pm 4.34 \times 10^{7 \mathrm{~B}}$ & $3.48 \times 10^{8} \pm 5.09 \times 10^{7 \mathrm{~A}}$ & 0.01 \\
\hline Xylose * & $3.63 \times 10^{6} \pm 1.05 \times 10^{6 \mathrm{~B}}$ & $8.69 \times 10^{6} \pm 1.23 \times 10^{6 \mathrm{~A}}$ & 0.01 \\
\hline
\end{tabular}

* Analysis based on ranked data; ${ }^{\dagger}$ values are measured as mean \pm SEM of area under the peak; ${ }^{\epsilon}$ significance determined at $p \leq 0.05$ based on FDR-corrected $p$-values; ${ }^{\mathrm{AB}}$ within-row represent groupings based on Fisher's LSD. 


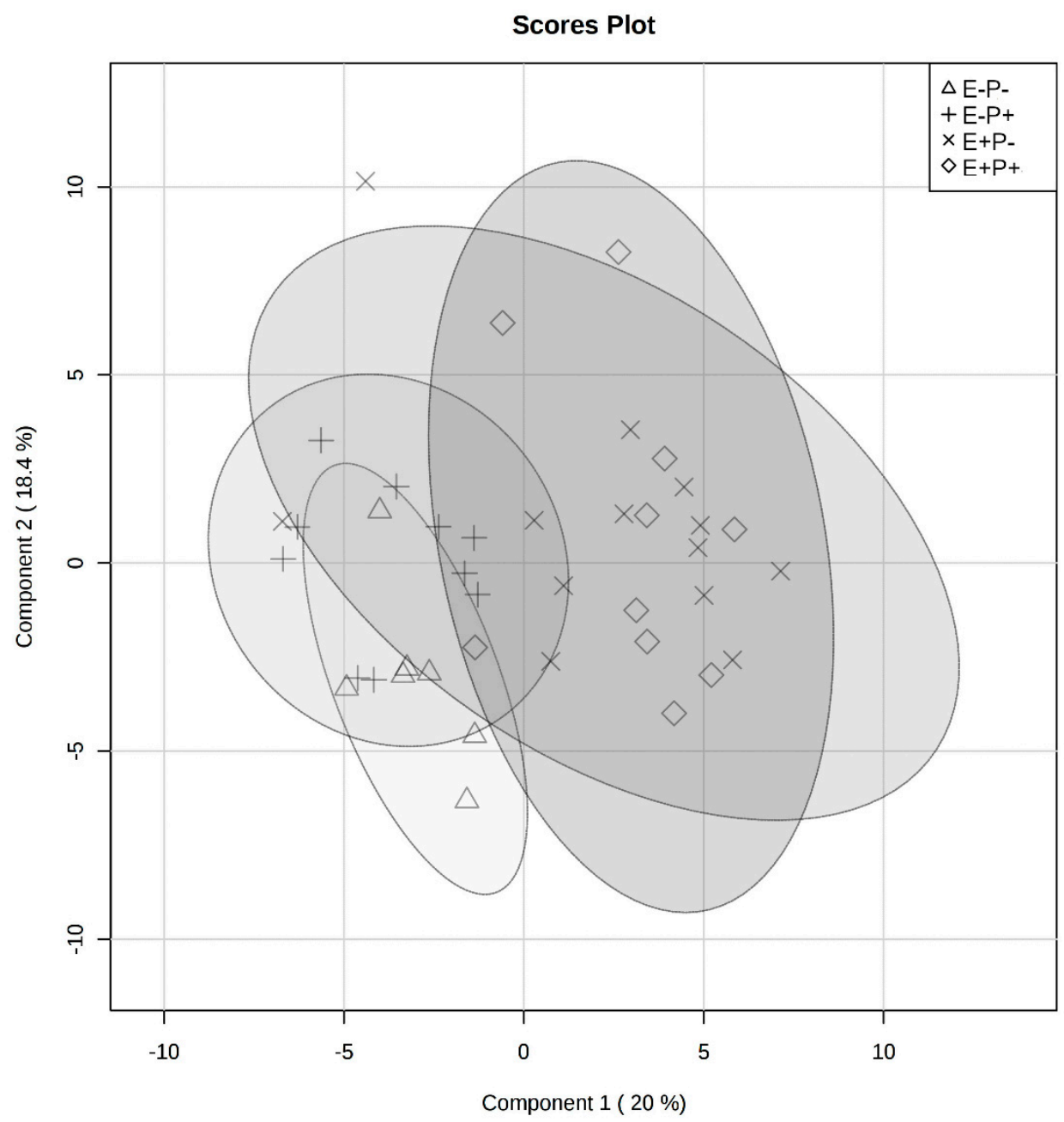

Figure 3. Partial least squares discriminant analysis (PLS-DA) visualizing differences in rumen fluid metabolomes between endophyte-free seed without isoflavones (triangle), endophyte-free with isoflavones (plus-sign), endophyte-infected without isoflavones (multiplication-sign), and endophyte-infected with isoflavones (diamond) treatment groups. Ellipse represents a 95\% confidence interval.

Table 2. Rumen fluid metabolic pathways impacted by seed type or isoflavone treatments.

\begin{tabular}{cccc}
\hline Pathway & FDR & Impact & $p$ Value \\
\hline & Seed Type & & \\
\hline Purine metabolism & $2.73 \times 10^{-4}$ & 0.338 & $6.89 \times 10^{-6}$ \\
Arginine and proline metabolism & $2.73 \times 10^{-4}$ & 0.075 & $1.07 \times 10^{-5}$ \\
Pentose and glucuronate interconversions & $3.42 \times 10^{-4}$ & 0 & $2.01 \times 10^{-5}$ \\
Beta-Alanine metabolism & $3.69 \times 10^{-4}$ & 0 & $2.89 \times 10^{-5}$ \\
Pyrimidine metabolism & $3.99 \times 10^{-4}$ & 0.494 & $5.92 \times 10^{-5}$ \\
Pantothenate and CoA biosynthesis & $3.99 \times 10^{-4}$ & 0.229 & $6.7 \times 10^{-5}$ \\
Aminoacyl-tRNA biosynthesis & $3.99 \times 10^{-4}$ & 0.2 & $7.81 \times 10^{-5}$ \\
Tyrosine metabolism & $3.99 \times 10^{-4}$ & 0 & $7.83 \times 10^{-5}$ \\
Novobiocin biosynthesis & $3.99 \times 10^{-4}$ & 0 & $7.83 \times 10^{-5}$ \\
Thiamine metabolism & $3.99 \times 10^{-4}$ & 0 & $7.83 \times 10^{-5}$ \\
Phenylalanine metabolism & $7.94 \times 10^{-4}$ & 0.001 & $1.71 \times 10^{-4}$ \\
\hline
\end{tabular}


Table 2. Cont.

\begin{tabular}{cccc}
\hline Pathway & FDR & Impact & $p$ Value \\
\hline Phenylalanine, tyrosine, and tryptophan biosynthesis & 0.001 & $4.60 \times 10^{-4}$ & $2.78 \times 10^{-4}$ \\
Carbapenem biosynthesis & 0.001 & 0 & $3.25 \times 10^{-4}$ \\
Butanoate metabolism & 0.001 & 0 & $3.25 \times 10^{-4}$ \\
Porphyrin and chlorophyll metabolism & 0.001 & 0 & $3.25 \times 10^{-4}$ \\
Pentose phosphate pathway & 0.003 & 0.07 & 0.001 \\
Amino sugar and nucleotide sugar metabolism & 0.004 & 0.109 & 0.001 \\
Glutathione metabolism & 0.004 & 0.014 & 0.002 \\
D-Glutamine and D-glutamate metabolism & 0.004 & 0.172 & 0.002 \\
Nitrogen metabolism & 0.004 & 0 & 0.002 \\
\hline Methane metabolism & 0.84824 & 0.154 & \\
Sulfur metabolism & 0.84824 & 0 & 0.032 \\
\hline
\end{tabular}

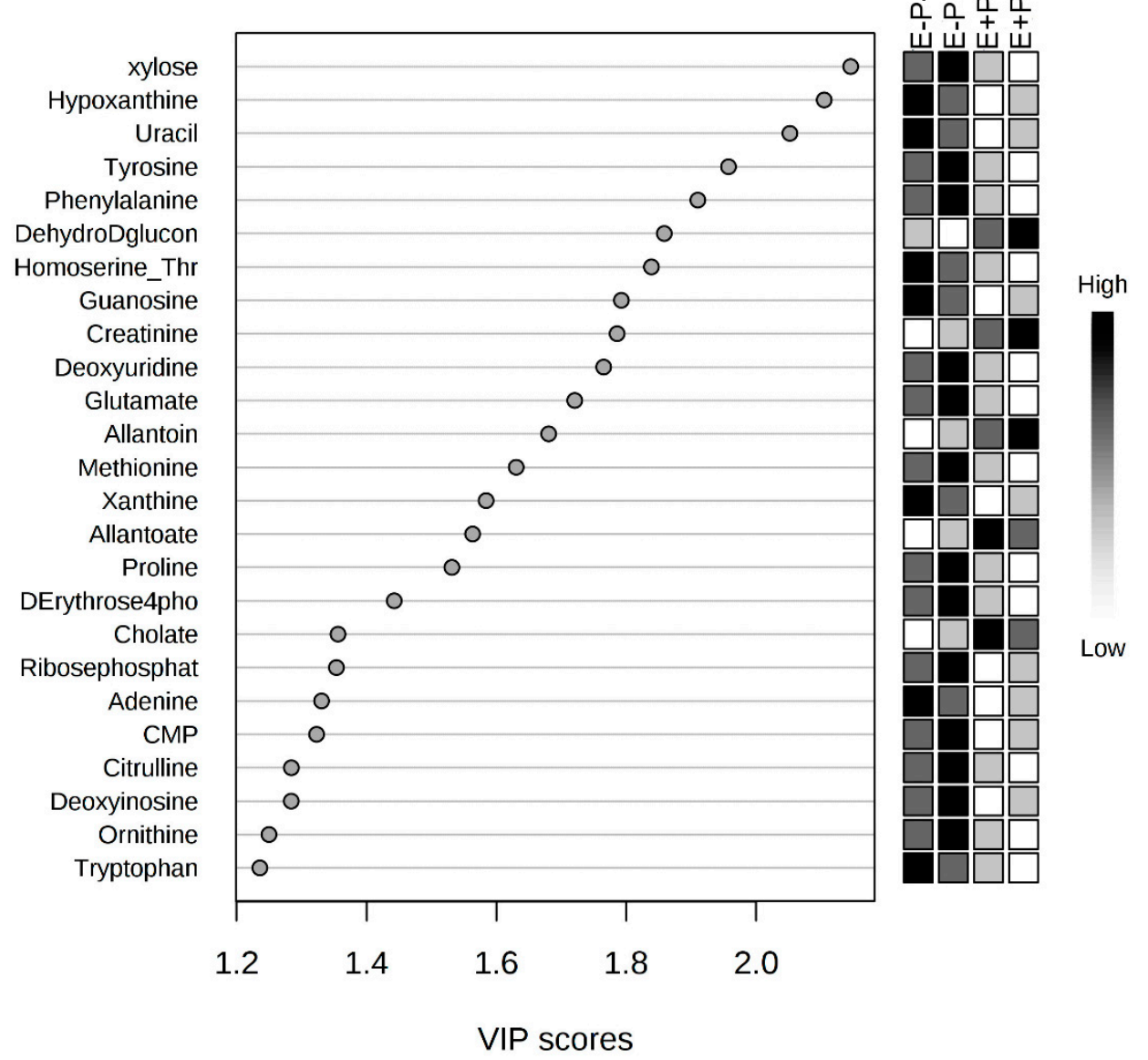

Figure 4. Variable importance in the projection (VIP) plot indicates xylose to have the greatest influence on the differences in rumen fluid metabolomes between all treatment groups. 
A

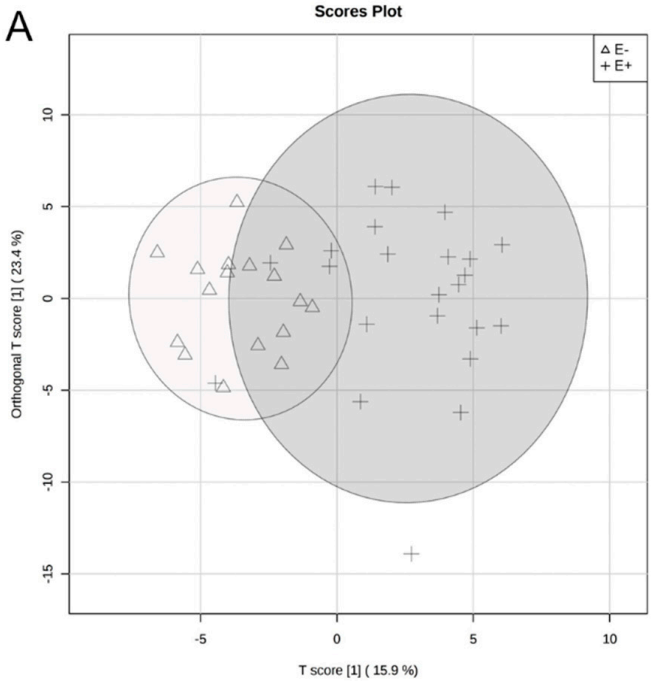

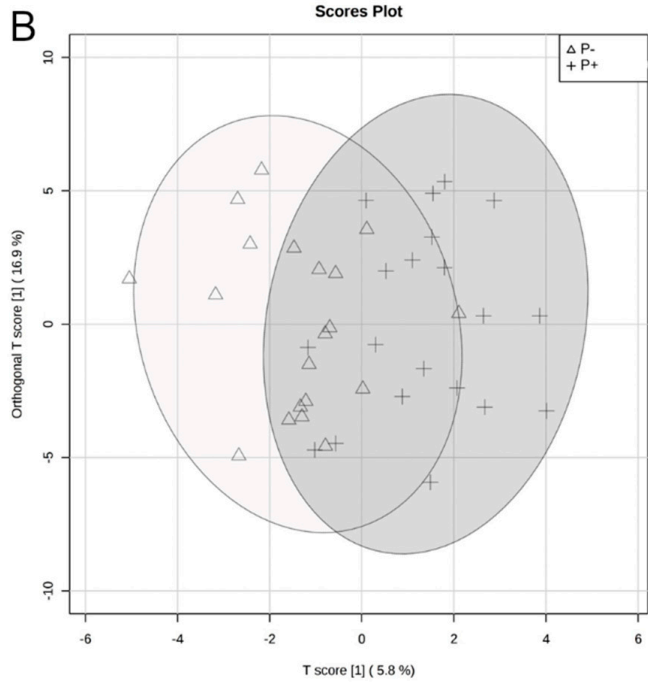

Figure 5. Orthogonal partial least squares discriminant analyses (O-PLS-DA) visualizing differences in rumen fluid metabolomes by seed type (A) and isoflavone (B) treatments. For seed type (A), endophyte-free (E-) steers are represented by a triangle and endophyte-infected $(\mathrm{E}+)$ steers by a plus-sign. For isoflavone treatments $(\mathbf{B})$, steers receiving isoflavones $(\mathrm{P}+)$ are represented by a plus-sign and without isoflavones $(\mathrm{P}-)$ by a triangle. Ellipse represents a $95 \%$ confidence interval.

A

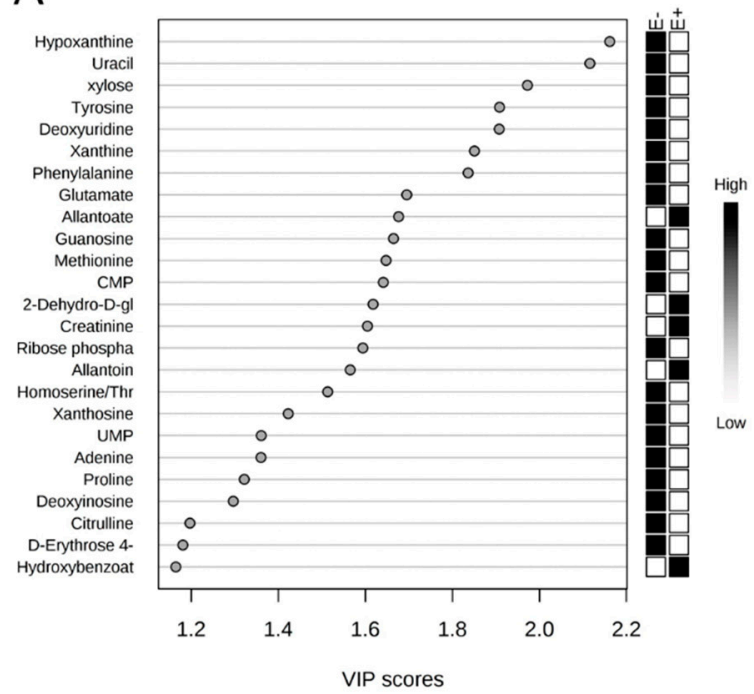

B

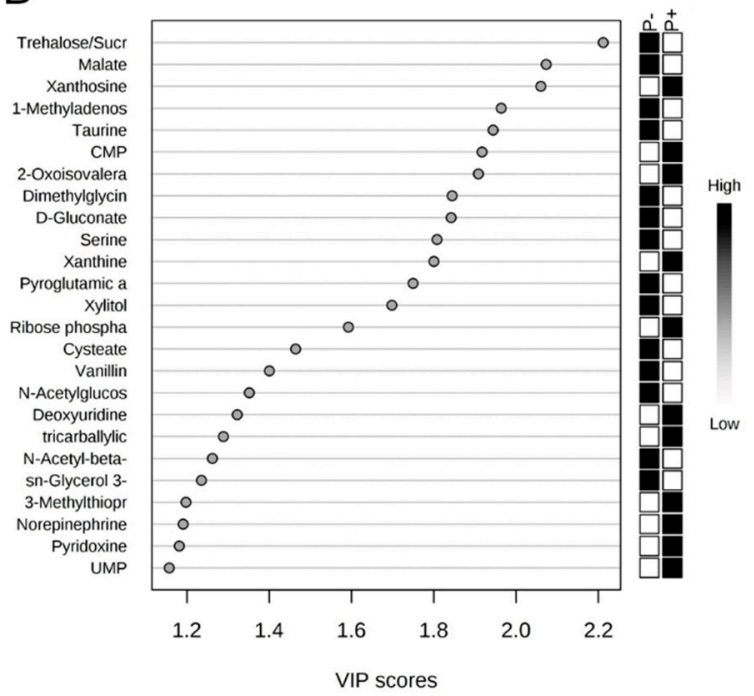

Figure 6. Variable importance in the projection (VIP) plots indicate hypoxanthine to have the greatest influence on the differences in rumen fluid metabolomes between endophyte-free (E-) and endophyte-infected $(\mathrm{E}+)$ seed treatment groups $(\mathbf{A})$, and trehalose sucrose to have the greatest influence between isoflavone treated $(\mathrm{P}+)$ and control $(\mathrm{P}-)$ groups $(\mathbf{B})$.

\subsection{Serum Metabolome}

All identified serum metabolites are presented in Supplementary File 2 with means and standard errors of the mean by treatment combination group. The serum metabolome was first analyzed by treatment combination group, isoflavone $\times$ seed type. The PLS-DA analysis indicated significant overlap among groups, with partial separation between the $\mathrm{E}+\mathrm{P}+$ and $\mathrm{E}-\mathrm{P}-$ groups (Figure 7). Correlation analyses were performed to determine the correlation of individual serum metabolites with the treatment combination groups and VIP were generated to determine the metabolites that contributed to variation in serum metabolomes among treatment combination groups. Pantothenate 
was negatively correlated with interaction of seed type $\times$ isoflavone treatments $(r=-0.29)$ and had the largest impact on metabolome differences, although not significant ( $p=0.07$; Figure 8 ).

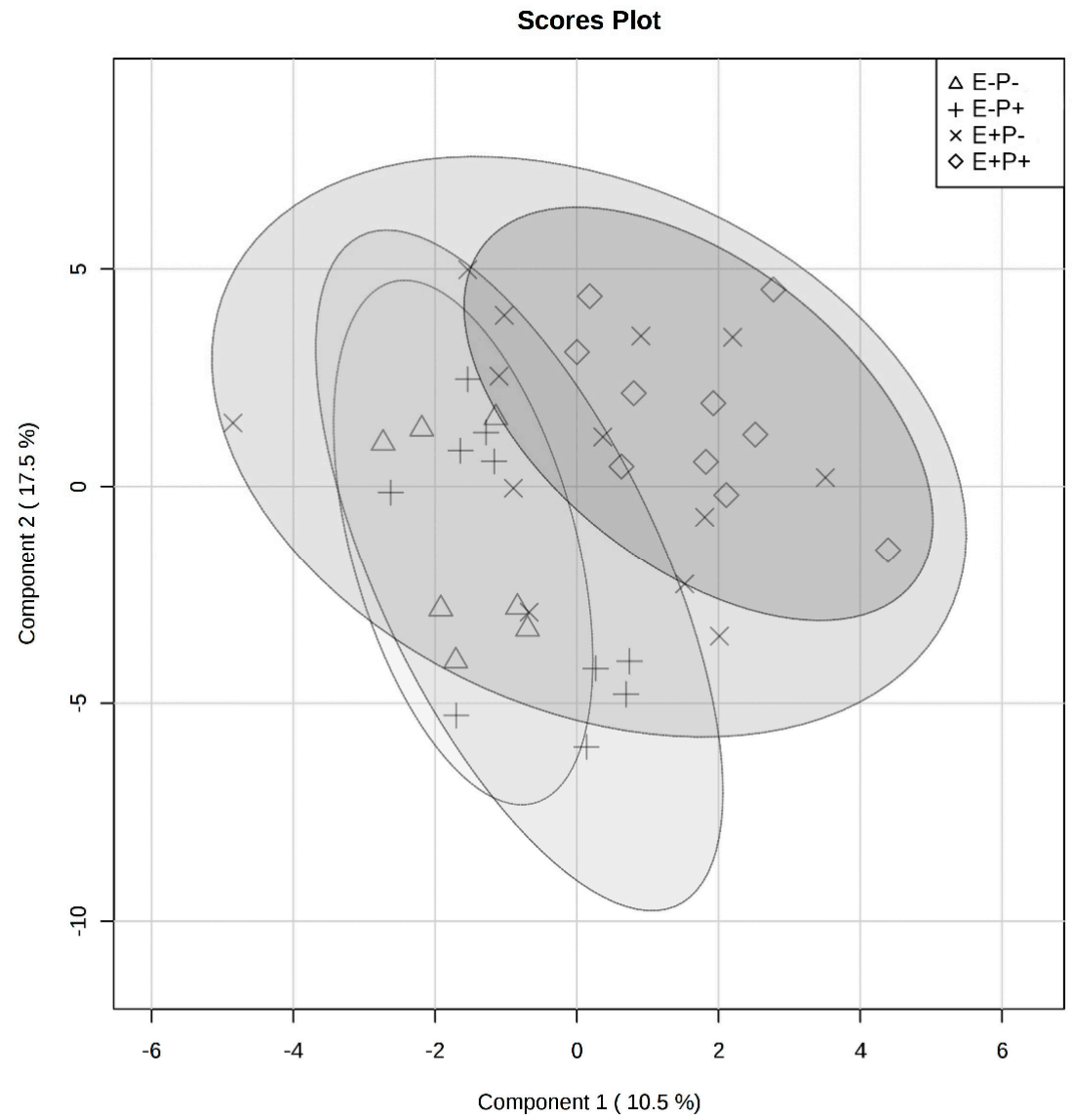

Figure 7. Partial least squares discriminant analysis (PLS-DA) visualizing differences in serum metabolomes between all treatment groups: endophyte-free seed without isoflavones (triangle), endophyte-free with isoflavones (plus-sign), endophyte-infected without isoflavones (multiplication-sign), and endophyte-infected with isoflavones (diamond). Ellipse represents a 95\% confidence interval.

Similar to rumen fluid, no individual serum metabolites or metabolic pathways were affected by the interaction of seed type and isoflavone treatment $(p>0.05)$. The serum metabolome was then analyzed by the main effects of seed type or isoflavone treatment. In order to visualize the difference in serum metabolomes, O-PLS-DA analyses were generated for seed type (Figure 9A) and isoflavone treatment (Figure 9B). For seed type, partial separation was observed between E+ and E- seed groups (Figure 9A). However, complete separation of serum metabolomes was illustrated between steers receiving isoflavones and those that did not receive isoflavones (Figure 9B). Correlation analysis indicated AMP was negatively correlated with seed treatment $(r=-0.35)$ and determined by VIP analysis to have the greatest impact on serum metabolome differences between $\mathrm{E}+$ and $\mathrm{E}-$ steers $(p=0.03$; Figure 10A). Between isoflavone treatment groups, citrulline was positively correlated $(r=0.47)$ and had the greatest impact on serum metabolome differences $(p=0.003$; Figure 10B). Seven metabolites differed significantly as a result of isoflavone treatment $(p<0.05$, Table 3 ), while no metabolites differed as a result of seed type $(p>0.05)$. Thirteen metabolic pathways differed $(p<0.05)$ as a result of seed type including glyoxylate and dicarboxylate metabolism; arginine biosynthesis; and alanine, aspartate, and glutamate metabolism $(p<0.01$; Table 4$)$. For isoflavone treatments, eight metabolic pathways were affected $(p<0.05)$, including pyrimidine metabolism and arginine and proline metabolism $(p<0.01$; Table 4$)$. 

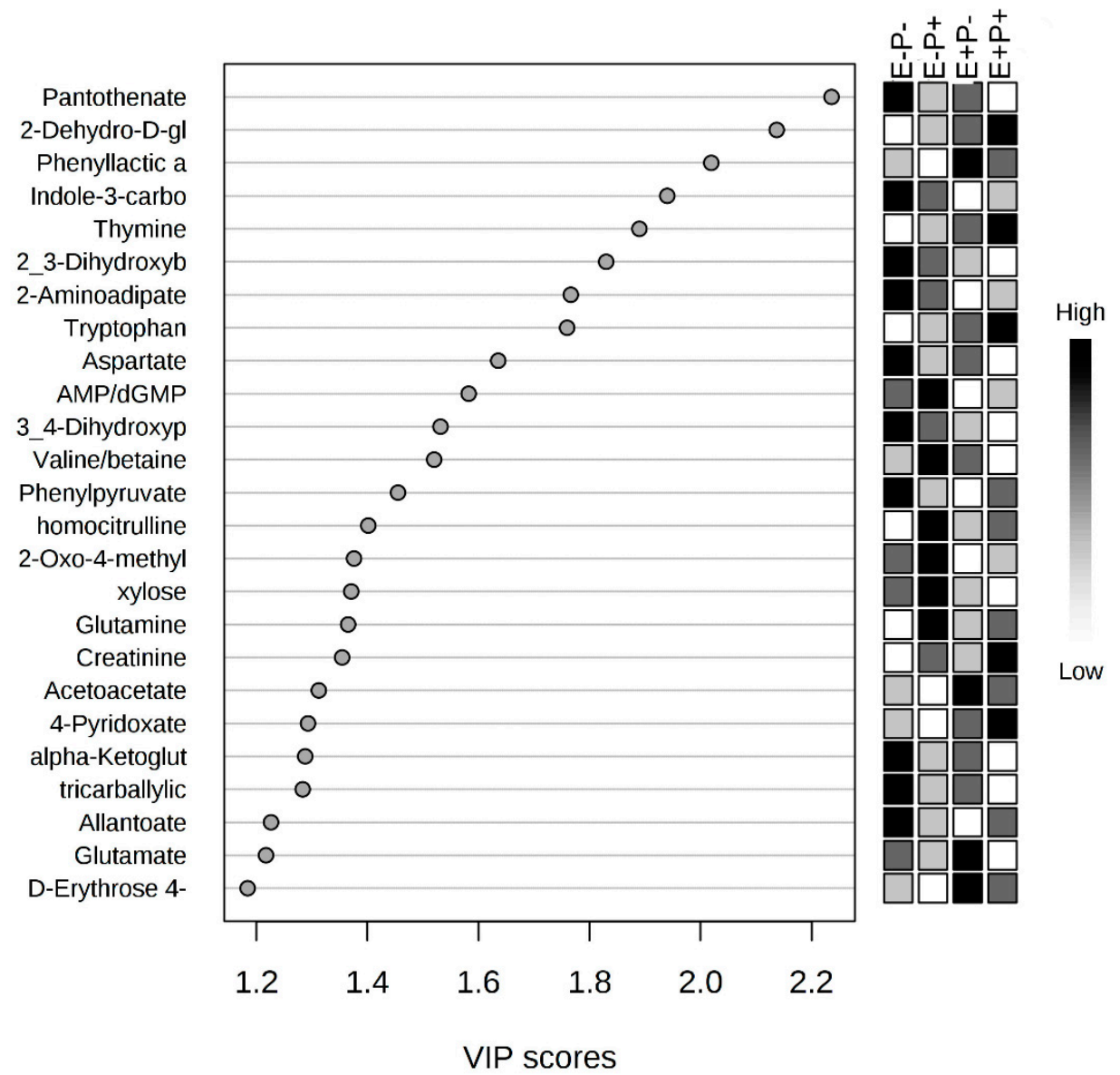

Figure 8. Variable importance in the projection (VIP) plot indicates pantothenate to have the greatest influence on the differences in serum metabolomes between all treatment groups.
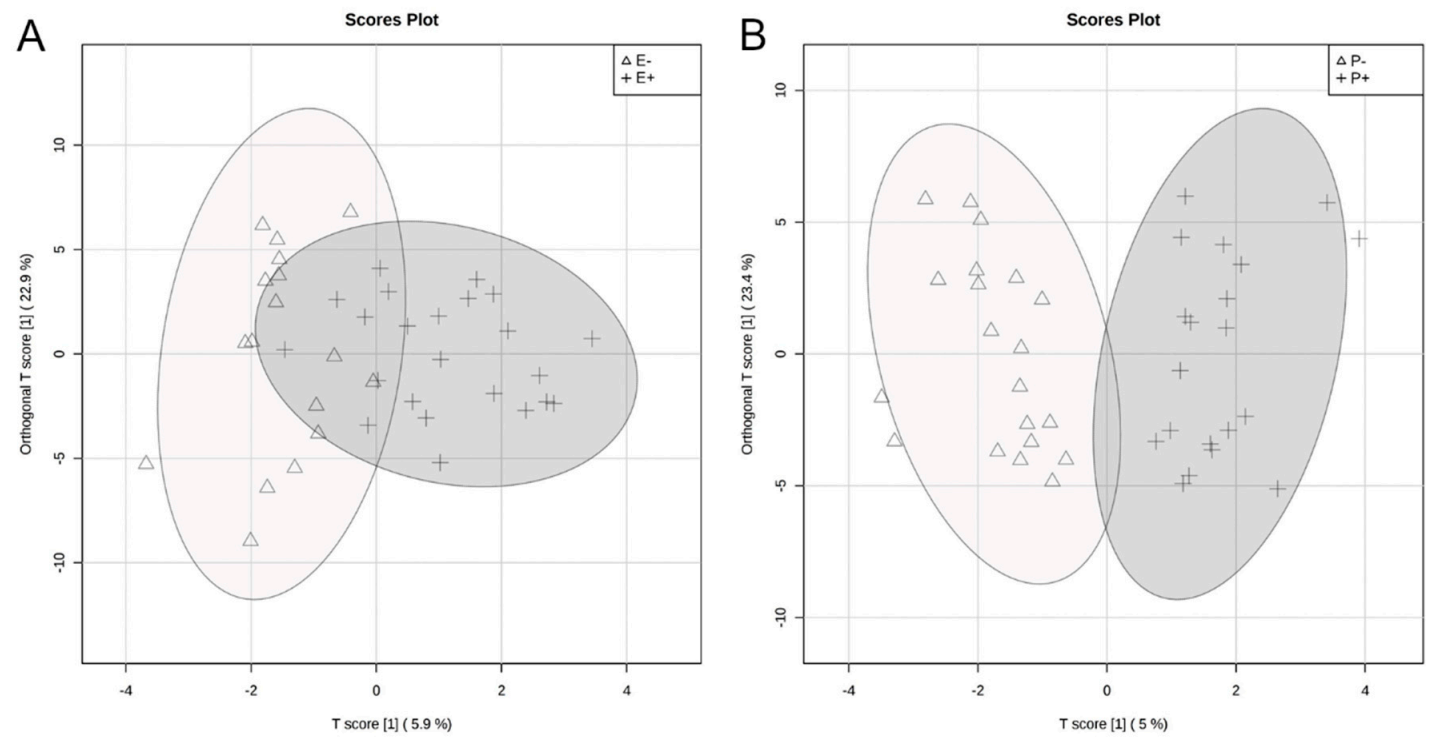

Figure 9. Orthogonal partial least squares discriminant analyses (O-PLS-DA) visualizing differences in serum metabolomes by seed type (A) and isoflavone (B) treatments. For seed type (A), endophyte-free (E-) steers are represented by a triangle and endophyte-infected $(\mathrm{E}+)$ steers by a plus-sign. For isoflavone treatments $(\mathbf{B})$, steers receiving isoflavones $(\mathrm{P}+)$ are represented by a plus-sign and without isoflavones $(\mathrm{P}-)$ by a triangle. Ellipse represents a $95 \%$ confidence interval. 
A

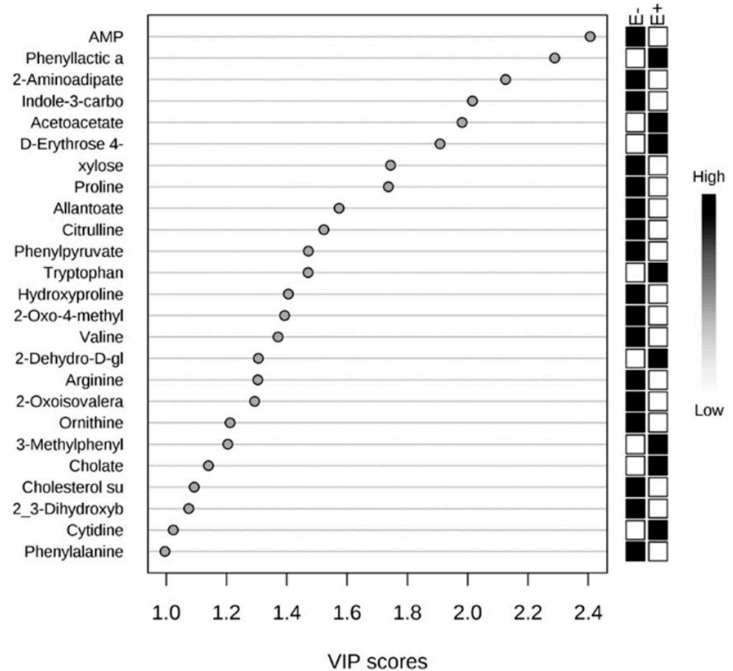

B

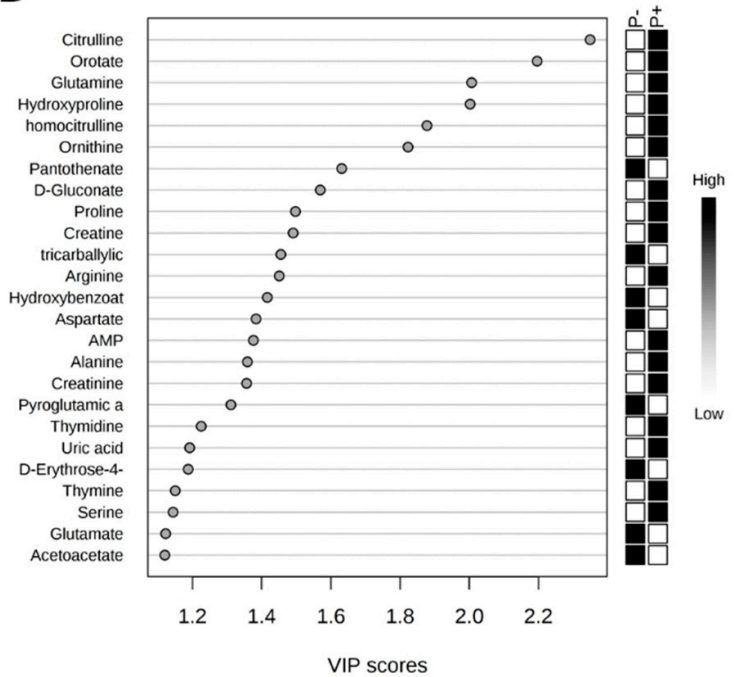

Figure 10. Variable importance in the projection (VIP) plot indicates AMP to have the greatest influence on the differences in serum metabolomes between endophyte-free (E-) and endophyte-infected $(E+)$ seed treatment groups $(\mathbf{A})$, and citrulline to have the greatest influence between isoflavone treated $(\mathrm{P}+)$ and control (P-) groups (B).

Table 3. Individual serum metabolites that significantly differed by isoflavone treatment.

\begin{tabular}{cccc}
\hline \multirow{2}{*}{ Metabolite } & \multicolumn{2}{c}{ Isoflavone Treatment $^{+}$} & \multirow{2}{*}{$\boldsymbol{p}$ Value $^{\boldsymbol{\epsilon}}$} \\
\cline { 2 - 4 } & $8.50 \times 10^{6} \pm 8.94 \times 10^{5}$ & $1.05 \times 10^{7} \pm 9.37 \times 10^{5}$ & 0.05 \\
\hline Histidine $^{*}$ & $1.51 \times 10^{6} \pm 4.89 \times 10^{5} \mathrm{~B}$ & $2.67 \times 10^{7} \pm 5.12 \times 10^{5} \mathrm{~A}$ & 0.01 \\
Cytidine $^{*}$ & $6.64 \times 10^{6} \pm 1.84 \times 10^{6} \mathrm{~B}$ & $1.51 \times 10^{7} \pm 1.93 \times 10^{6 \mathrm{~A}}$ & 0.01 \\
Pantothenate & $1.47 \times 10^{6} \pm 1.28 \times 10^{5 \mathrm{~B}}$ & $2.02 \times 10^{6} \pm 1.35 \times 10^{5 \mathrm{~A}}$ & 0.02 \\
Homocysteine & $1.94 \times 10^{8} \pm 1.14 \times 10^{7 \mathrm{~B}}$ & $2.37 \times 10^{8} \pm 1.19 \times 10^{7} \mathrm{~A}$ & 0.03 \\
Allantoin & $9.68 \times 10^{5} \pm 1.40 \times 10^{5 \mathrm{~B}}$ & $1.41 \times 10^{6} \pm 1.44 \times 10^{5 \mathrm{~A}}$ & 0.05 \\
GABA & $8.35 \times 10^{5} \pm 6.25 \times 10^{4}$ & $1.04 \times 10^{6} \pm 6.51 \times 10^{4}$ & 0.05 \\
Methylhistidine & &
\end{tabular}

* Analysis based on ranked data; ${ }^{\dagger}$ values are measured as mean \pm SEM of area under the peak; ${ }^{\epsilon}$ significance determined at $p \leq 0.05$ based on FDR-corrected $p$-values; ${ }^{\mathrm{AB}}$ within-row represent groupings based on Fisher's LSD.

Table 4. Serum metabolic pathways affected by seed type and isoflavone treatments.

\begin{tabular}{cccc}
\hline Pathway & FDR & Impact & $p$ Value \\
\hline \multicolumn{1}{c}{ Seed Type } & & & \\
\hline Glyoxylate and dicarboxylate metabolism & 0.013 & 0.11 & 0.005 \\
Arginine biosynthesis & 0.013 & 0.51 & 0.006 \\
Alanine, aspartate, and glutamate metabolism & 0.015 & 0.73 & 0.007 \\
Cysteine and methionine metabolism & 0.051 & 0.14 & 0.024 \\
Glycine, serine, and threonine metabolism & 0.054 & 0.16 & 0.029 \\
Ubiquinone and other terpenoid-quinone biosynthesis & 0.054 & 0 & 0.029 \\
Aminobenzoate degradation & 0.054 & 0 & 0.029 \\
Vitamin B6 metabolism & 0.069 & 0.05 & 0.039 \\
Monobactam biosynthesis & 0.069 & 0 & 0.041 \\
Lysine biosynthesis & 0.069 & 0 & 0.041 \\
Tryptophan metabolism & 0.069 & 0.06 & 0.042 \\
Cyanoamino acid metabolism & 0.07 & 0 & 0.044 \\
& 0.076 & 0 & 0.05 \\
\hline
\end{tabular}


Table 4. Cont.

\begin{tabular}{cccc}
\hline Pathway & FDR & Impact & $p$ Value \\
\hline Isoflavone Treatment & & & \\
\hline Pyrimidine metabolism & 0.151 & 0.37 & 0.007 \\
Arginine and proline metabolism & 0.151 & 0.19 & 0.008 \\
D-glutamine and D-glutamate metabolism & 0.151 & 0.17 & 0.013 \\
Nitrogen metabolism & 0.151 & 0 & 0.013 \\
Arginine biosynthesis & 0.151 & 0.51 & 0.015 \\
Glutathione metabolism & 0.173 & 0.01 & 0.02 \\
Purine metabolism & 0.209 & 0.09 & 0.029 \\
Glyoxylate and dicarboxylate metabolism & 0.269 & 0.13 & 0.045 \\
\hline
\end{tabular}

\section{Discussion}

The overall reductions in animal performance due to fescue toxicosis are estimated to cost the cattle industry over $\$ 2$ billion annually $[13,14]$. Therefore, it is vital to discover management methods to reduce the impact and improve the efficiency of beef production. The objective of the current study was to use untargeted metabolomics to evaluate tall fescue seed and isoflavone consumption effects on metabolic intermediates, outputs, and pathways in the rumen and serum.

The metabolomes of the rumen and circulatory environments were first compared, independent of treatment groups, which observed distinctly unique metabolomes according to principal coordinate and abundance analyses. Highly abundant metabolites in each environment were not shared or only present in low abundances between the two environments. The metabolites identified between these different body systems are likely a result of the specific physiological functions of each system in the ruminant. The microbiome is a major contributor to rumen metabolome, as it supplies over $70 \%$ of the ruminant's required nutrients [15]. These microbes are highly metabolically active in order to break down feedstuffs and release metabolites to complement host metabolism of which metabolites originate from the plants and other feedstuffs consumed [16]. Therefore, the majority of metabolites identified in the rumen are of xenobiotic origin. By evaluating the rumen metabolome, the effects of tall fescue seed and isoflavone consumption on rumen microbial metabolic processes can be inferred. The serum metabolites, however, are a result of absorbed metabolic products from the rumen and other organs. Tissues throughout the body produce intermediary metabolites from protein, carbohydrate, and lipid metabolism for energy production to perform physiological functions. These metabolites are then absorbed into the blood and can travel through the circulatory system to other tissues for further catabolic or anabolic processing. Therefore, the metabolome of the circulatory system is typically dominated by endogenous metabolites. Because of this systemic nature, metabolites in blood have been used as potential biomarkers to predict feed utilization [17] and production parameters [18], as well as evaluate responses to disease $[19,20]$ and stress [21]. Evaluating the serum metabolome will determine the systemic metabolic response to tall fescue seed and isoflavone supplementation. Together, the effects on individual metabolites and metabolic pathways in rumen fluid and serum will determine how alterations in microbial and host metabolism contribute to symptoms of fescue toxicosis or the benefits isoflavones may contribute to mitigate these detrimental impacts.

Reductions in average daily gain and delayed development of beef cattle are a major consequence of fescue toxicosis $[8,22]$. The rumen microbiome is crucial for providing nutrients needed by the host for energy requirements and muscle development. As the microbiome has previously been shown to be affected by consuming endophyte infected tall fescue [12,23], the metabolites and other products produced by the rumen microorganisms may be altered, potentially contributing to reductions in growth and feed efficiency. The metabolites produced by the rumen microorganisms are a result of the richness of the rumen microbiome. Several of these metabolites released may be related to the consumption of ergot alkaloids concentrated on the endophyte infected tall fescue seed. Many of the rumen metabolites have a relationship with purine, carbohydrate, and nucleic acid metabolism, such as 
hypoxanthine, xylose, and uracil, respectively [24,25]; these metabolites are related to feed efficiency parameters. Clemmons et al. [26] found that these metabolites are bio-indicators of feed efficiency in cattle showing low residual feed intake. Interestingly, they are negatively correlated to seed type in the rumen fluid of the current study; it is evident that animals are being affected by the detrimental symptoms of tall fescue toxicosis, failing to gain weight, and being less feed-efficient. Additionally, we did not observe a large number of different metabolites because of the reduction of the rumen microbiome. As a normal rumen environment, the significant presence of other metabolites, which are crucial for the ergot alkaloids metabolism and production of volatile fatty acids, was expected and improves feed efficiency and rumen microbial richness.

Vasoconstriction, induced by ergot alkaloids, occurs throughout the body, resulting in multiple observed symptoms of fescue toxicosis [4,6]. Specifically, the contractility of the mesenteric vasculature surrounding the digestive tract is affected by the consumption of ergot alkaloids, potentially affecting nutrient absorption and subsequent host metabolism [5]. However, the consumption of isoflavones promotes vasodilation to increase blood flow and mitigate fescue toxicosis effects [10]. Ideally, oxygen and nutrient delivery to tissues is improved, thus benefiting host metabolism. Evaluating serum metabolites during induced fescue toxicosis and treatment with isoflavones may indicate the changes in metabolism systemically. The serum metabolome in the current study was greatly affected by isoflavone treatments with complete separation of animals' global serum metabolomes between treatment groups; no metabolites differed as a result of seed type. Citrulline was identified as having the greatest influence on serum metabolomes between isoflavone treatment groups. Citrulline is an intermediary metabolite in the urea cycle, a metabolic process crucial for providing non-protein nitrogen to the ruminant [27]. As isoflavones inhibit hyper-ammonia producing bacteria in the rumen, this reduces the amount of protein degradation, leading to decreased ammonia and nitrogen availability [11,28]. Multiple metabolic pathways related to the urea cycle such as arginine biosynthesis and metabolism, pyrimidine metabolism, and nitrogen metabolism were affected in serum metabolites by isoflavone treatments. Therefore, the effect of citrulline on the serum metabolome due to isoflavone treatment may be a result of changes in the urea cycle by improving protein availability to the ruminant for muscle development.

Pantothenate was considered to be a major contributor to differences observed in the global serum metabolome among all treatment combinations, but was significantly higher in abundance in steers receiving isoflavone treatment. Previous studies have indicated different levels of pantothenate in the serum of animals differing in feed efficiency, with more feed efficient animals having greater serum levels of pantothenate $[17,26]$. Pantothenate is a key intermediary metabolite for the formation of Coenzyme A, which is crucial for amino acid and lipid metabolism for ruminant muscle development [29]. Additionally, the majority of metabolic pathways affected by isoflavone treatment in the current study were related to amino acid metabolism and biosynthesis. As animals experiencing fescue toxicosis often have low average daily gains [8], the use of isoflavone supplementation may mitigate the weight gain and growth consequences of fescue toxicosis. The greater amount of available pantothenate in the serum of animals consuming isoflavones, with changes in the urea cycling of the ruminant, may improve growth and muscle development in steers affected by fescue toxicosis.

A classic symptom of fescue toxicosis is a significant reduction of prolactin secretion; this is due to the similar homology of ergot alkaloids with the neurotransmitter dopamine. Ergot alkaloids will act as an agonist by binding dopamine receptors, preventing the release of prolactin [3,30]. Tyrosine is a precursor for the generation of the neurotransmitter dopamine [31]. The current study found tyrosine metabolism to be affected by seed type in the rumen; tyrosine metabolic pathways are influenced as the signals for dopamine production are reduced during fescue toxicosis. Additionally, the study found tryptophan metabolism was affected by seed type in the serum. Tryptophan is a key amino acid in regulating protein synthesis, specifically in muscle development, of multiple species [32,33]. The effects of tryptophan on muscle development are through the IGF-1 pathway [33]. Tryptophan is a precursor to the neurotransmitter serotonin, which stimulates the production of 
IGF-1 [34]. Supplementation of rumen protected tryptophan improved weight gain and feed efficiency of ruminants $[35,36]$. The observed impact of seed type on tryptophan metabolism in the serum may indicate reduced production of serotonin and subsequent IGF-1 signaling for muscle development. Together, the impacts of fescue toxicosis on tyrosine and tryptophan metabolism were also observed previously in the plasma of steers consuming endophyte-infected or endophyte-free seed $[37,38]$. Therefore, tall fescue seed consumption alters neurotransmitter development, leading to commonly observed symptoms of fescue toxicosis.

\section{Conclusions}

In conclusion, the rumen metabolome was largely impacted by seed type, while the serum metabolome was influenced by isoflavone supplementation. In the rumen, the impact of the seed type involved carbohydrate and nucleic acids metabolism products of the fescue seed diet inclusion. In the serum, differences in global metabolomes and individual metabolites involved in urea cycling and amino acid metabolic pathways were identified in animals receiving isoflavones and those that did not. Although the low dose of isoflavones administered to cattle indicated effects on the serum and rumen metabolome, further research is needed to determine the effects at other doses. Future applications may lead to the dietary inclusion of isoflavones to reduce the harmful effects of tall fescue toxicosis.

\section{Materials and Methods}

All experimental procedures involving animals were approved by the University of Tennessee Institutional Animal Care and Use Committee. The ethic approval code (IACUC) was 2540-0617 and was approved on 20 June 2017.

\subsection{Experimental Design and Sample Collection}

Experimental design, animal treatments, and sample collection methods have been previously described in Melchior et al. [12]. Briefly, this study used 36 purebred Angus steers of approximately eight months of age weighing $250 \pm 20 \mathrm{~kg}$ from Ames Plantation in Grand Junction, TN. Steers were transported to the Plateau Research and Education Center (PREC) in Crossville, TN for the trial, as previously described [12]. Steers were allowed a $10 \mathrm{~d}$ acclimation period to the diet formulated to provide $11.57 \%$ crude protein and $76.93 \%$ total digestible nutrients (DM basis). The GrowSafe System(C) (GrowSafe Systems Ltd., Calgary, AB, Canada) was used to monitor feed intake. Prior to the beginning of the trial, steers were genotyped for the DRD2 receptor gene, which can influence cattle's response to fescue toxicity [12]. Using this information, the study was blocked on DRD2 genotype, implementing a randomized complete block design. A $2 \times 2$ factorial arrangement of treatments was utilized with two types of tall fescue including endophyte-infected $(\mathrm{E}+)$ and endophyte-free fescue $(\mathrm{E}-)$, and treatment with Promensil $\subseteq(\mathrm{P}+)$ or without $(\mathrm{P}-)$ to provide red clover isoflavones. This combination of treatments resulted in four treatment groups: (1) endophyte-infected seed without Promensil $(\mathrm{E}+\mathrm{P}-)$, (2) endophyte-infected with Promensil (E+P+), (3) endophyte-free without Promensil (E-P-), and (4) endophyte-free with Promensil (E-P+). Within each genotype block, steers were randomly assigned to treatments with nine steers per treatment group. The feed trial occurred over 21 days. In order to provide a consistent amount of ergot alkaloids, endophyte-infected tall fescue seed heads were incorporated into feed to provide a minimum of $0.011 \mathrm{mg}$ ergovaline plus ergovalinine $\times \mathrm{kg}$ of body weight $^{-1}$ (BW) per day [3]. Seed heads were ground through a $5 \mathrm{~mm}$ screen using a Wiley Mill (Thomas Scientific, Swedesboro, NJ, USA) and included in feed. A total of $943 \mathrm{mg}$ of isoflavones was provided daily before morning feeding based on previously established dosages [10] using a $28.4 \mathrm{~g}$ bolus (Torpac, Inc., Fairfield, NJ, USA) to provide $24.7 \mathrm{~g}$ of Promensil. Melchior et al. [12] previously reported the analysis and information of the components present in Promensil, and steers' response to endophyte-infected seed and altered performance parameters. On the final day of the trial (day 21), approximately $9 \mathrm{~mL}$ of blood was collected from the coccygeal vein using a serum separator tube (Corvac, Sherwood Medical., St. Louis, MO, USA), and approximately $100 \mathrm{~mL}$ of rumen content 
was collected via oro-gastric lavage. Blood samples were centrifuged at $2000 \times g$ and $4{ }^{\circ} \mathrm{C}$ for 20 min, and serum was transferred to $2 \mathrm{~mL}$ microvials and stored at $-80^{\circ} \mathrm{C}$ until metabolite extractions. Rumen samples were centrifuged at $6000 \times g$ at $4{ }^{\circ} \mathrm{C}$ for $20 \mathrm{~min}$. The supernatant was aspirated and filtered through a $0.22 \mu \mathrm{m}$ syringe filter, transferred to $2 \mathrm{~mL}$ microvials, and stored at $-80{ }^{\circ} \mathrm{C}$ until metabolite extraction.

\subsection{Metabolite Extraction and Identification}

Metabolites were extracted and analyzed as previously described [17] at the UTK Biological and Small Molecule Mass Spectrometry Core (BSMMSC). Briefly, $50 \mu \mathrm{L}$ of filtered rumen fluid and $50 \mu \mathrm{L}$ of serum from each steer were extracted using $0.1 \%$ formic acid in acetonitrile/water/methanol (2:2:1) using a previously described method [39]. Mobile phases consisted of A: 97:3 water/methanol with $11 \mathrm{mM}$ tributylamine and $15 \mathrm{mM}$ acetic acid and $\mathrm{B}$ : methanol, and gradient consisting of the following: $0.0 \mathrm{~min}, 0 \% \mathrm{~B} ; 2.5 \mathrm{~min} \%$ B; $5.0 \mathrm{~min}, 20 \% \mathrm{~B} ; 7.5 \mathrm{~min}, 20 \% \mathrm{~B} ; 13 \mathrm{~min}, 55 \% \mathrm{~B} ; 15.5 \mathrm{~min}, 95 \% \mathrm{~B}$; $18.5 \mathrm{~min}, 95 \% \mathrm{~B} ; 19 \mathrm{~min}, 0 \% \mathrm{~B}$; and $25 \mathrm{~min}, 0 \% \mathrm{~B}$; Synergy Hydro-RP column $(100 \times 2 \mathrm{~mm}, 2.5 \mu \mathrm{m}$ particle size) was used to separate metabolites. The flow rate was set to a constant $200 \mu \mathrm{L} / \mathrm{min}$ and the column temperature was kept at $25^{\circ} \mathrm{C}$. A Dionex UltiMate 3000 UPLC system (Thermo Fisher Scientific, Waltham, MA) with an autosampler tray maintained at $4{ }^{\circ} \mathrm{C}$ was used to introduce a $10 \mu \mathrm{L}$ sample to an Exactive Plus Orbitrap MS (Thermo Fisher Scientific, Waltham, MA, USA) using negative electrospray ionization (ESI) with a capillary temperature of $300{ }^{\circ} \mathrm{C}$; spray voltage of $3 \mathrm{kV}$; and nitrogen sheath and sweep gas at 25 and 3 units, respectively. Data acquisition was done in negative ion mode with a full-scan covering the range of $72-1000 \mathrm{~m} / \mathrm{z}$ at 140,000 resolution with automatic gain control of $3 \times 10^{6}$ ions [40]. Metabolites are annotated using exact mass of the $[\mathrm{M}-\mathrm{H}]-( \pm 5 \mathrm{pmm})$ ion and known retention times $( \pm 0.3 \mathrm{~min})$ generated from an in-house curated database. The database was created from the analysis of authentic standards and consisted of 300 compounds across various metabolic pathways, focusing on water soluble metabolites in pathways conserved among a diverse array of organisms.

\subsection{Metabolite Identification}

Data were analyzed similarly to those of Clemmons et al. [17]. The Xcalibur MS software (Thermo Electron Corp., Waltham, MA) was used to produce raw files, which were then converted to mzML format using ProteoWizard [41]. The software package Metabolomic Analysis and Visualization Engine for LC-MS Data (MAVEN) [42] was used to identify peaks using converted mzML files. MAVEN identifies metabolites based on non-linear retention time correction and calculates peak areas across samples, using a preliminary mass error of $\pm 20 \mathrm{ppm}$ and a retention time window of $5 \mathrm{~min}$. The UTK BSMMSC used a library of 263 retention time-accurate $m / z$ pairs taken from MS1 spectra for final metabolite annotations. These are based on expansions of previous work [40] and have been replicated at the UTK BSMMSC. The eluted peak of the annotated metabolite had to be found within 2 min of the expected retention time, and the metabolite mass had to be within \pm 5 ppm of the expected value to be identified as a known compound. The compound area of each peak was calculated using the Quan Browser function of the Xcalibur MS Software (Thermo Electron Corp., Waltham, MA, USA).

\subsection{Data Analysis}

Metabolomic data were analyzed using MetaboAnalyst 4.0 [43] and SAS 9.4 (SAS Institute, Cary, NC, USA). For data analysis in MetaboAnalyst, data were first pre-processed. Metabolite data were filtered using interquartile range, normalized by median, log transformed, and auto scaled prior to analysis in MetaboAnalyst 4.0. First, the rumen and serum metabolomes were collectively compared in order to determine similarity of rumen fluid and serum metabolomes for possible overlap or comparison. The rumen and serum metabolomes were visualized using orthogonal partial least squares discriminant analysis (O-PLS-DA) and partial least squares discriminant analysis (PLS-DA) with 2000 permutations. Model fitting for the O-PLS-DA was assessed using R2Y with prediction 
power determined using the Q2 metric. A heatmap was generated with the top 25 metabolites to illustrate differences in serum and rumen fluid metabolomes by steer. Next, rumen fluid and serum metabolomes were analyzed separately by treatment combination (i.e., isoflavone $\times$ seed type), isoflavone, and seed type. Within each of these, data were visualized via PCA and O-PLS-DA with 2000 permutations, and metabolomes by individual steers were illustrated using heatmaps. Correlation analyses between the top 25 metabolites and treatment groups or combinations were performed for both rumen fluid and serum metabolomes, as well as variable importance in projections (VIP) of the top 25 metabolites. Finally, pathway analyses were performed to determine metabolic pathways that were significantly impacted in rumen fluid and serum by isoflavone or seed type using a global test with relative-betweenness centrality and a reference pathway of Escherichia coli K-12 MG1655 [44].

Raw data were further analyzed in SAS 9.4 (SAS Institute, Cary, NC, USA), First, data were analyzed for normality using the UNIVARIATE procedure, and were considered normal with a Shapiro-Wilk statistic of $\geq 0.90$ and visual observation of histograms and $q-q$ plots. Data that were normally distributed were analyzed with a mixed model analysis of variance (ANOVA) using the GLIMMIX procedure with fixed effects of seed type, isoflavone treatment, and their interaction with the random effect of genotype $\times$ isoflavone $\times$ seed type. Metabolites that did not follow a normal distribution were fixed ranked and then analyzed using a mixed model ANOVA using the GLIMMIX procedure with fixed effects of seed type, isoflavone treatment, and their interaction with random effect of genotype $\times$ isoflavone $\times$ seed type.

Supplementary Materials: The following are available online at http://www.mdpi.com/2072-6651/12/12/744/s1, Supplementary File 1: Means and standard error of the means of all metabolites in the rumen fluid between treatment groups; Supplementary File 2: Means and standard error of the means of all metabolites in the serum between treatment groups.

Author Contributions: Conceptualization, E.A.M.-T. and P.R.M.; Formal analysis, B.A.C.; Funding acquisition, P.R.M.; Investigation, T.B.A.-S. and J.F.C.; Methodology, B.A.C., G.E.B., M.D.F., J.L.K., H.J., J.P.G., K.J.M. and P.R.M.; Project administration, P.R.M.; Resources, E.A.M.-T.; Visualization, T.B.A.-S. and B.A.C.; Writing-original draft, T.B.A.-S., B.A.C., J.F.C., K.J.M. and P.R.M.; Writing-review \& editing, T.B.A.-S., E.A.M.-T., B.A.C., J.F.C., J.L.K., K.J.M. and P.R.M. All authors have read and agreed to the published version of the manuscript.

Funding: This research was funded by the University of Tennessee CVM, Center for Excellence in Livestock and Human Diseases.

Acknowledgments: We acknowledge the USDA-NIFA Hatch/Multistate Project W4177-TEN00524-Enhancing the Competitiveness and Value of U.S. Beef. We thank Ames Plantation, UT Plateau Research and Education Center, Rebecca Payton, Lezek Wojakiewicz, and Gloria Gellin (USDA-ARS) for their assistance. We also thank Shawn Campagna and Hector Castro at the UTK Biological and Small Molecule Mass Spectrometry Core (BSMMSC).

Conflicts of Interest: The authors declare no conflict of interest.

\section{References}

1. Poole, R.K.; Poole, D.H. Impact of Ergot Alkaloids on Female Reproduction in Domestic Livestock Species. Toxins 2019, 11, 364. [CrossRef] [PubMed]

2. Moore, J.D.; Carlisle, A.E.; Nelson, J.A.; McCulley, R.L. Fungal endophyte infection increases tall fescue's survival, growth, and flowering in a reconstructed prairie. Restor. Ecol. 2019, 27, 1000-1007. [CrossRef]

3. Klotz, J.L. Activities and Effects of Ergot Alkaloids on Livestock Physiology and Production. Toxins 2015, 7, 2801-2821. [CrossRef] [PubMed]

4. Strickland, J.R.; Aiken, G.E.; Klotz, J.L. Ergot Alkaloid Induced Blood Vessel Dysfunction Contributes to Fescue Toxicosis. Forage Grazinglands 2009, 7, 1-7. [CrossRef]

5. $\quad$ Egert, A.M.; Kim, D.H.; Schrick, F.N.; Harmon, D.L.; Klotz, J.L. Dietary exposure to ergot alkaloids decreases contractility of bovine mesenteric vasculature. J. Anim. Sci. 2014, 92, 1768-1779. [CrossRef]

6. Poole, D.H.; Lyons, S.E.; Poole, R.K.; Poore, M.H. Ergot alkaloids induce vasoconstriction of bovine uterine and ovarian blood vessels. J. Anim. Sci. 2018, 96, 4812-4822. [CrossRef]

7. Al-Haidary, A.; Spiers, D.; Rottinghaus, G.E.; Garner, G.B.; Ellersieck, M.R. Thermoregulatory ability of beef heifers following intake of endophyte-infected tall fescue during controlled heat challenge. J. Anim. Sci. 2001, 79, 1780-1788. [CrossRef] 
8. Stuedemann, J.A.; Hoveland, C.S. Fescue Endophyte: History and Impact on Animal Agriculture. J. Prod. Agric. 1988, 1, 39-44. [CrossRef]

9. Roberts, C.A.; Andrae, J. Tall Fescue Toxicosis and Management. Crop Manag. 2004, 3, 1-18. [CrossRef]

10. Aiken, G.E.; Flythe, M.D.; Kagan, I.A.; Ji, H.; Bush, L.P. Mitigation of Ergot Vasoconstriction by Clover Isoflavones in Goats (Capra hircus). Front. Vet. Sci. 2016, 3, 17. [CrossRef]

11. Harlow, B.E.; Flythe, M.D.; Kagan, I.A.; Aiken, G.E. Biochanin A (an Isoflavone Produced by Red Clover) Promotes Weight Gain of Steers Grazed in Mixed Grass Pastures and Fed Dried-Distillers' Grains. Crop Sci. 2017, 57, 506-514. [CrossRef]

12. Melchior, E.A.; Smith, J.K.; Schneider, L.G.; Mulliniks, J.T.; Bates, G.E.; Flythe, M.D.; Klotz, J.L.; Ji, H.; Goodman, J.P.; Lee, A.R.; et al. Effects of endophyte-infected tall fescue seed and red clover isoflavones on rumen microbial populations and physiological parameters of beef cattle. Transl. Anim. Sci. 2018, 3, 315-328. [CrossRef] [PubMed]

13. Hoveland, C.S. Importance and economic significance of the Acremonium endophytes to performance of animals and grass plant. Agric. Ecosyst. Environ. 1993, 44, 3-12. [CrossRef]

14. Kallenbach, R.L. BILL E. KUNKLE INTERDISCIPLINARY BEEF SYMPOSIUM: Coping with tall fescue toxicosis: Solutions and realities. J. Anim. Sci. 2015, 93, 5487-5495. [CrossRef] [PubMed]

15. Bergman, E.N. Energy contributions of volatile fatty acids from the gastrointestinal tract in various species. Physiol. Rev. 1990, 70, 567-590. [CrossRef] [PubMed]

16. Fontanesi, L. Metabolomics and livestock genomics: Insights into a phenotyping frontier and its applications in animal breeding. Anim. Front. 2016, 6, 73-79. [CrossRef]

17. Clemmons, B.A.; Mihelic, R.I.; Beckford, R.C.; Powers, J.B.; Melchior, E.A.; McFarlane, Z.D.; Cope, E.R.; Embree, M.M.; Mulliniks, J.T.; Campagna, S.R.; et al. Serum metabolites associated with feed efficiency in black angus steers. Metabolomics 2017, 13, 147. [CrossRef]

18. Wu, X.; Sun, H.-Z.; Xue, M.; Wang, D.; Guan, L.L.; Liu, J. Serum metabolome profiling revealed potential biomarkers for milk protein yield in dairy cows. J. Proteom. 2018, 184, 54-61. [CrossRef]

19. Aich, P.; Jalal, S.; Czuba, C.; Schatte, G.; Herzog, K.; Olson, D.J.; Ross, A.R.; Potter, A.A.; Babiuk, L.A.; Griebel, P.J. Comparative Approaches to the Investigation of Responses to Stress and Viral Infection in Cattle. OMICS A J. Integr. Biol. 2007, 11, 413-434. [CrossRef]

20. Zandkarimi, F.; Vanegas, J.; Fern, X.; Maier, C.S.; Bobe, G. Metabotypes with elevated protein and lipid catabolism and inflammation precede clinical mastitis in prepartal transition dairy cows. J. Dairy Sci. 2018, 101, 5531-5548. [CrossRef]

21. Liao, Y.; Hu, R.; Wang, Z.; Peng, Q.; Dong, X.; Zhang, X.; Zou, H.; Pu, Q.; Xue, B.; Wang, L. Metabolomics Profiling of Serum and Urine in Three Beef Cattle Breeds Revealed Different Levels of Tolerance to Heat Stress. J. Agric. Food Chem. 2018, 66, 6926-6935. [CrossRef] [PubMed]

22. Crawford, R.J.; Forwood, J.R.; Belyea, R.L.; Garner, G.B. Relationship between Level of Endophyte Infection and Cattle Gains on Tall Fescue. J. Prod. Agric. 1989, 2, 147-151. [CrossRef]

23. Mote, R.S.; Hill, N.S.; Skarlupka, J.H.; Turner, Z.B.; Sanders, Z.P.; Jones, D.P.; Suen, G.; Filipov, N.M. Response of Beef Cattle Fecal Microbiota to Grazing on Toxic Tall Fescue. Appl. Environ. Microbiol. 2019, 85. [CrossRef] [PubMed]

24. Saleem, F.; Bouatra, S.; Guo, A.C.; Psychogios, N.; Mandal, R.; Dunn, S.M.; Ametaj, B.N.; Wishart, D.S. The Bovine Ruminal Fluid Metabolome. Metabolomics 2013, 9, 360-378. [CrossRef]

25. Artegoitia, V.M.; Foote, A.P.; Lewis, R.M.; Freetly, H.C. Rumen Fluid Metabolomics Analysis Associated with Feed Efficiency on Crossbred Steers. Sci. Rep. 2017, 7, 1-14. [CrossRef]

26. Clemmons, B.A.; Martino, C.; Powers, J.B.; Campagna, S.R.; Voy, B.H.; Donohoe, D.R.; Gaffney, J.; Embree, M.M.; Myer, P.R. Rumen Bacteria and Serum Metabolites Predictive of Feed Efficiency Phenotypes in Beef Cattle. Sci. Rep. 2019, 9, 1-8. [CrossRef]

27. Alemneh, T.; Getahun, D.; Akeberegn, D.; Getabalew, M.; Zewdie, D. Urea Metabolism and Recycling in Ruminants. Biomed. J. Sci. Tech. Res. 2019, 20, 14790-14796. [CrossRef]

28. Flythe, M.D.; Kagan, I. Antimicrobial Effect of Red Clover (Trifolium pratense) Phenolic Extract on the Ruminal Hyper Ammonia-Producing Bacterium, Clostridium sticklandii. Curr. Microbiol. 2010, 61, 125-131. [CrossRef]

29. Leonardi, R.; Zhang, Y.-M.; Rock, C.O.; Jackowski, S. Coenzyme A: Back in action. Prog. Lipid Res. 2005, 44, 125-153. [CrossRef] 
30. Sibley, D.R.; Creese, I. Interactions of ergot alkaloids with anterior pituitary D-2 dopamine receptors. Mol. Pharmacol. 1983, 23, 585-593.

31. Fernstrom, J.D. Dietary Precursors and Brain Neurotransmitter Formation. Annu. Rev. Med. 1981, 32, 413-425. [CrossRef]

32. Lin, F.D.; Smith, T.K.; Bayley, H.S. A Role for Tryptophan in Regulation of Protein Synthesis in Porcine Muscle. J. Nutr. 1988, 118, 445-449. [CrossRef] [PubMed]

33. Dukes, A.; Davis, C.; El Refaey, M.; Upadhyay, S.; Mork, S.; Arounleut, P.; Johnson, M.H.; Hill, W.D.; Isales, C.M.; Hamrick, M.W. The aromatic amino acid tryptophan stimulates skeletal muscle IGF1/p70s6k/mTor signaling in vivo and the expression of myogenic genes in vitro. Nutrition 2015, 31, 1018-1024. [CrossRef] [PubMed]

34. Musumeci, G.; Trovato, F.; Avola, R.; Imbesi, R.; Castrogiovanni, P. Serotonin/growth hormone/insulin-like growth factors axis on pre- and post-natal development: A contemporary review. OA Anat. 2013, 1, 12. [CrossRef]

35. Ma, H.; Cheng, J.; Zhu, X.; Jia, Z. 2011. Effects of rumen-protected tryptophan on performance, nutrient utilization and plasma tryptophan in cashmere goats. Afr. J. Biotechnol. 2011, 10, 5806-5811.

36. Lee, J.S.; Priatno, W.; Ghassemi Nejad, J.; Peng, D.Q.; Park, J.S.; Moon, J.O.; Lee, H.G. Effect of dietary rumen-protected L-Tryptophan supplementation on growth performance, blood hematological and biochemical profiles, and gene expression in Korean native steers under cold environment. Animals 2019, 9, 1036. [CrossRef]

37. Mote, R.S.; Hill, N.S.; Uppal, K.; Tran, V.T.; Jones, D.P.; Filipov, N.M. Metabolomics of fescue toxicosis in grazing beef steers. Food Chem. Toxicol. 2017, 105, 285-299. [CrossRef]

38. Mote, R.S.; Hill, N.S.; Skarlupka, J.H.; Tran, V.T.; Walker, D.I.; Turner, Z.B.; Sanders, Z.P.; Jones, D.P.; Suen, G.; Filipov, N.M. Toxic tall fescue grazing increases susceptibility of the Angus steer fecal microbiota and plasma/urine metabolome to environmental effects. Sci. Rep. 2020, 10, 2497. [CrossRef]

39. Kamphorst, J.J.; Fan, J.; Lu, W.; White, E.; Rabinowitz, J.D. Liquid Chromatography-High Resolution Mass Spectrometry Analysis of Fatty Acid Metabolism. Anal. Chem. 2011, 83, 9114-9122. [CrossRef]

40. Lu, W.; Clasquin, M.F.; Melamud, E.; Amador-Noguez, D.; Caudy, A.A.; Rabinowitz, J.D. Metabolomic Analysis via Reversed-Phase Ion-Pairing Liquid Chromatography Coupled to a Stand Alone Orbitrap Mass Spectrometer. Anal. Chem. 2010, 82, 3212-3221. [CrossRef]

41. Chambers, M.C.; MacLean, B.; Burke, R.D.; Amodei, D.; Ruderman, D.L.; Neumann, S.; Gatto, L.; Fischer, B.; Pratt, B.; Egertson, J.D.; et al. A cross-platform toolkit for mass spectrometry and proteomics. Nat. Biotechnol. 2012, 30, 918-920. [CrossRef] [PubMed]

42. Clasquin, M.F.; Melamud, E.; Rabinowitz, J.D. LC-MS Data Processing with MAVEN: A Metabolomic Analysis and Visualization Engine. Curr. Protoc. Bioinform. 2012, 37. [CrossRef]

43. Chong, J.; Soufan, O.; Li, C.; Caraus, I.; Li, S.; Bourque, G.; Wishart, D.S.; Xia, J. MetaboAnalyst 4.0: Towards more transparent and integrative metabolomics analysis. Nucleic Acids Res. 2018, 46, W486-W494. [CrossRef] [PubMed]

44. Kanehisa, M.; Goto, S.; Sato, Y.; Kawashima, M.; Furumichi, M.; Tanabe, M. Data, information, knowledge and principle: Back to metabolism in KEGG. Nucleic Acids Res. 2013, 42, D199-D205. [CrossRef]

Publisher's Note: MDPI stays neutral with regard to jurisdictional claims in published maps and institutional affiliations.

(C) 2020 by the authors. Licensee MDPI, Basel, Switzerland. This article is an open access article distributed under the terms and conditions of the Creative Commons Attribution (CC BY) license (http://creativecommons.org/licenses/by/4.0/). 